\title{
Understanding health care avoidance and initial help-seeking behavior in German veterans: a theory of planned behavior
}

This article was published in the following Dove Press journal:

Psychology Research and Behavior Management

\author{
Stefan Siegel' \\ Simone Dors' \\ Loni Brants' \\ Katrin Schuy' \\ Heinrich $\mathrm{Rau}^{2}$ \\ 'Department for Psychiatry \\ and Psychotherapy, Charite \\ Universitatsmedizin Berlin, Berlin, \\ Germany; ${ }^{2}$ Center for PTSD, Military \\ Hospital Berlin, Berlin, Germany
}

Objective: To gain initial insights into salient beliefs of former German soldiers (veterans) about the use of mental health services.

Data source: Narrative interviews with former German soldiers (veterans) were conducted in 2016.

Data collection/extraction method: Forty-three interviews were transcribed and analyzed thematically based on the theoretical framework of the theory of planned behavior. From within the behavorial, normative, and control beliefs, the salient beliefs were identified.

Principal findings: Four groups of salient beliefs were identified, described, and named: "Autarky", "Ineffectiveness", "Heteronomy", and "Incapacity".

Conclusion: Interventions and campaigns addressing these four specific groups of beliefs may lead to higher health service use rates. However, as a result of methodological limitations of the study design, the conclusion remains tentative.

Keywords: veterans, military personnel, barriers to care, mental health service/utilization

\section{Introduction}

Since 9/11 the number of missions abroad engaged in by the German Armed Forces (GAF, German: Bundeswehr) has increased steadily. Missions abroad are associated with more traumatic events and higher rates of post-traumatic stress disorder (PTSD) than in the general population. ${ }^{1}$ Stress further increases after soldiers leave military service and there is a chance of developing late-onset forms of PTSD. ${ }^{2}$ Despite fulfilling diagnostic criteria and despite the existence of efficient manualized trauma-focused psychotherapy, not all soldiers seek help or treatment for their problems. ${ }^{1}$ Little is known to explain why military personnel in Germany avoid or then eventually seek health care. According to a widely used behavioral model of health service use, ${ }^{3}$ among others, especially contextual factors, individual beliefs influence the intention to engage in help-seeking behavior. Empirical findings suggest that individual factors such as attitudes, knowledge, social norms, and perceived control are interrelated in a complex way with more contextual factors such as enabling factors and need factors. ${ }^{4}$ However, we know little about how they might be interrelated and influence the intention of an individual to seek help. The Theory of Planned Behavior provides a theoretical framework for understanding, explaining, and predicting an individuals' behavior by examining their salient beliefs about the behavior, which contributes to their intention to engage in a certain behavior. ${ }^{5}$ Three conceptually independent determinants
Correspondence: Stefan Siegel Department for Psychiatry and Psychotherapy, Charite Universitatsmedizin Berlin, Chariteplatz I, I0II7 Berlin, Germany Tel +4930450529312 Fax +4930450529998 Email stefan.siegel@charite.de 
of intention toward the use of mental health service or helpseeking are postulated by this theory. The first determinant, "Attitude toward Behavior", refers to the degree to which an individual has made a favorable or unfavorable evaluation of health service use behavior and, therefore, intends to engage in it or not ("Do I want to do it?"). The second determinant, postulated by the Theory of Planned Behavior, "Subjective Norms", refers to the subjectively perceived social pressure to engage in or not to engage in the behavior ("Should I do it?"). The third determinant, "Perceived Behavioral Control" or "Control Beliefs", refers to the degree to which an individual thinks that they will succeed in performing the anticipated behavior. The final group of beliefs includes beliefs about actual capabilities and resources as well as one's own experiences or experiences of others with the behavior (“Can I do it?”).

To optimize the predictability of a Theory of Planned Behavior, belief salience should be elicited in pilot work from the research population itself. According to Ajzen, this is of the utmost importance, the more the examined population has been molded by their own set of attitudes, behavioral expectations, social norms, and morals. The military seems to be such a population. However, thus far there has been no research on the salient health beliefs of members of the GAF. We, therefore, decided to use interview data from the German Veterans' Readjustment Study to take a closer look at health beliefs among this population. The objectives were to obtain initial insights into the shared salient beliefs of former German soldiers regarding the use of mental health services.

\section{Materials and methods}

\section{Research context, recruitment, and sample selection}

The study was approved by the ethics committee of the Charite Universitatsmedizin Berlin (Approval Number EA1/250/14). We designed a homepage which could be accessed through links on the social media channels of German veterans' organizations and associations. Potential participants could register there to take part in the study. All in all, 103 veterans established contact. Five of them could not be reached by means of their contact information given. Preliminary telephone interviews were conducted with the remaining 98 veterans to gather information concerning inclusion criteria, sociodemographic and military background, actual quality of life, and their motivations for taking part in the study. They were considered to have met our inclusion criterion if they were a former GAF soldier with a minimum of 29 days service abroad.
From these 98 veterans, some participants were selected for detailed, in-depth, face-to-face interviews. The selection process for participants was driven by theory-based criteria. ${ }^{9}$ Instead of achieving representativity for this pilot study, we wanted to reach a potentially large and diverse sample. ${ }^{6}$ Therefore, veterans with and without diagnosed mental disorders, veterans with different perceived illness severity or quality of life, and veterans of different military rank from different regions of Germany and from different age groups were selected. The second criterion was theoretical saturation. ${ }^{8}$ In addition to these theory-based criteria, opportunistic criteria (eg, accessibility of the interviewee) were applied. ${ }^{9}$ After 43 interviews, all three criteria, in particular theoretical saturation, were met and, therefore, the sampling process was stopped at this point. These 43 interviews form the basis of the research questions in the German Veterans' Readjustment Study.

\section{Participants}

The sample was composed of participants of different ranks (from soldiers to senior officers), different organizational units (Army, Navy, Air Force, Joint Support Service, and Medical Service), and veterans from different federal states of Germany (12 out of 16$)$. Four (9.3\%) veterans were female, the age span of the participants was between 26 and 69 years (mean age=41.1; SD=12.3). Some veterans had just left the GAF, others had been civilians for several years. According to the veterans interviewed, 19 (44\%) suffered from a service-incurred disability (German: Wehrdienstbeschadigung), three (6.9\%) of them were in "protection time" (German: Schutzzeit), that is, a time span used for clinical and occupational rehabilitation in which soldiers cannot be discharged from military service.

\section{Data collection}

In all in-depth interviews, two researchers visited the interviewees either at their home or - if they were hospitalized at the hospital. One researcher conducted the interview, the other one was responsible for equipment, field observations, the minutes and note taking. Before the interview started, the interviewees were given all relevant information concerning the aim, scope, and methodology of the study. Evaluation of data and data confidentiality was explained. The interviewees then gave their informed consent in writing. All interviews were recorded as MP3 files and later transcribed by an external transcription service, which adhered to strict confidentiality regulations. Transcription was carried out using guidelines which specified that the oral version was 
to be transcribed verbatim, but dialects and function words were to be omitted, and punctuation was adapted to facilitate legibility. ${ }^{7}$ The complete body of recorded interviews consists of 37 hours 6 minutes of recorded material with the average interview lasting 52 minutes.

\section{Data analysis}

The data were analyzed thematically to gain deep insights into the veterans' perceptions and to capture the complexities of the phenomena in question. The overall approach was inspired by grounded theory methodology; however, the goal was not to generate an own theoretical framework but to animate and particularize the well-established theory of planned behavior referring to the specific population. The transcribed and anonymized data were coded using the software MAXQDA ${ }^{\circledR} 12$. The objective of this coding process was to identify underlying patterns in the data. In the first step, members of the research team (KS, SS, LB, and SD) coded the interviews independently of one another (open coding) following an open-minded approach and not looking for specific theoretical concepts. Validation proved to be an important means of following a reflexive, flexible, and critical approach as it also meant analyzing and considering the researchers' preexisting concepts and experiences to establish critical distance from the data. Following the communicative validation method, the second step categories were formed and their relations were organized (axial coding). After preliminary categories were established, the coding process was repeated and adapted to the newly found relationships between codings. In the last step, empirically validated conclusions were drawn (selective coding), and for this paper, the categories found were related to the concepts of the theory of planned behavior.

\section{Quality standards and rigor}

High-quality standards and strict rigor in the scientific process were guaranteed by an ethical, theory-based, and iterative approach in sampling, data collection, and data processing. All team members took part regularly in methodology training, research workshops, and external research supervision. The research team included medical doctors and psychologists, both with and without clinical experience, with and without military background, and with and without deployment experience, thus incorporating a multidisciplinary perspective. This made possible different views and perspectives on the data. In addition to team-based communicative validation, we used peer consulting, formal consensus building processes, and the presentation of preliminary results to internal and external experts.

\section{Results}

The qualitative analysis of the veterans' narratives helped to identify the salient health beliefs that contributed to the German veterans' reluctance to seek help both in military and civilian contexts. An overview of our results along with typical quotations from our participants is given in Figure 1.

\section{Behavioral beliefs}

In our data, behavioral beliefs ("Do I want to do it?") seem to be an important factor in hindering the use of mental health services. There seem to be two main reasons why veterans do not want to use mental health services. The first reason is that they have no intention to seek professional help because according to them - they have no need for help from others, they think they are able to handle the problem on their own ("autarky"). When going into further detail, the underlying beliefs might be connected to shared concepts of masculinity and/or soldiers morals, ie, strength, self-sufficiency, mental stability, and emotional reserve. In addition, learned individual coping or problem-solving strategies seem to play an important role. The second reason that hinder help-seeking behavior are beliefs or attitudes that counseling therapy in general or at least counseling therapy with a civilian counselor does not help ("ineffectiveness"). Again, the underlaying belief seemed to be "why would talking about feelings work?" ie, very rigid and stereotypical views on masculinity inculcated by the military culture. However, there have also been some veterans who had a positive attitude toward helpseeking behavior. This positive attitude was strongly linked to the conviction that psychotherapeutic counseling indeed helps solving problems or might even heal their suffering.

\section{Normative beliefs}

In our sample of veterans, normative beliefs seem to play the major role in seeking professional help regarding a mental problem. Actually coming into contact with a mental health professional was strongly linked to a significant other, for example, family member, life partner, or immediate superiors, exerting pressure to seek help. We, therefore, postulate a direct link from normative beliefs to actual behavior. On the other hand, social pressure not to go to a troop physician was commonly reported. Seeking help might lead to temporary disablement and might, therefore, not be tolerated by family, coworkers, and employers. 


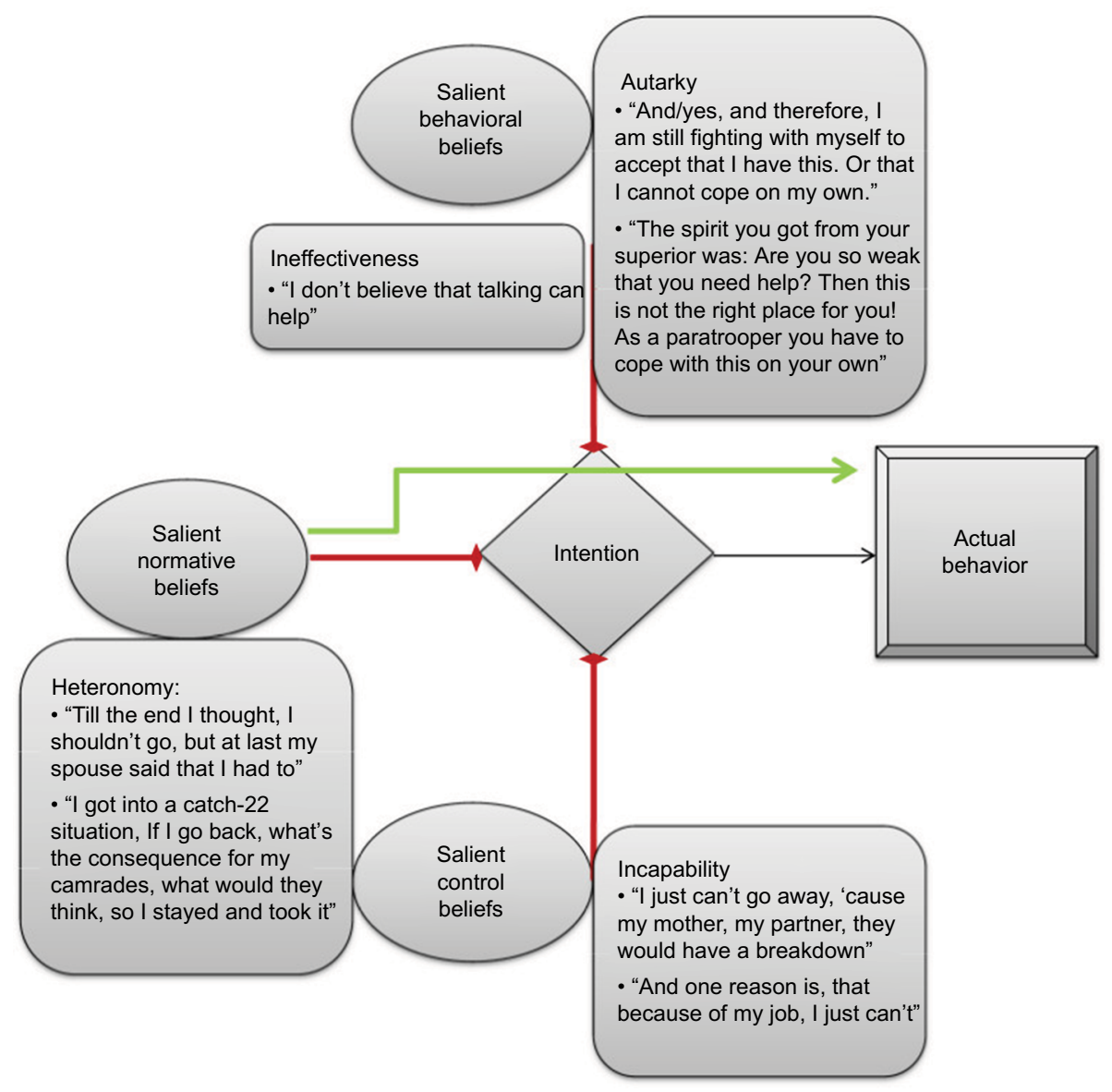

Figure I Overview of the theory of planned behavior in veterans seeking professional help for mental health problems.

It is an interesting result that within the group of former military personnel we explored, subjective norms are a major issue in determining health behavior. This population seems in a certain and especially intense manner to be influenced by the beliefs or thoughts of what others think about them or what others tell them to do ("heteronomy").

\section{Control beliefs}

Some veterans were fearful about disclosing mental health problems to others because of fear of stigmatization and social exclusion. Another underlying belief was that disclosure of a mental health problem might lead to problems in their career or at least their social reputation they feared real discrimination.

We think that these fears are best subsumed under control beliefs. Some veterans stated that they wanted to seek help (positive attitude toward mental health service) and they also believed that they should seek help (normative beliefs), but the aforementioned fears hindered them from doing so, they figuratively "can't", they experience a subjective lack of control over the (imagined) reactions of others.
Another point was the lack of individual enabling factors, ie, organizational or financial resources to initiate helpseeking behavior. These include concerns about being able to care for their families ("Incapability").

\section{Discussion}

This study for the first time elicited the salient beliefs about mental health service use from a sample of respondents from the research population. Our thematic analysis of narrative interview data on German veterans made it possible to identify certain salient beliefs that are related to the helpseeking behavior or to avoidance of health service use by this specific population of former military personnel: "Autarky", "Ineffectiveness", "Heteronomy", and "Incapability". As the theory of planned behavior postulates, a set of empirically generated beliefs may better predict behavior than a set of beliefs intuitively selected by the researcher.

However, there are some limitations regarding our result. A major limitation of our study may be that we know little about the population of German veterans as a whole. Therefore, we cannot answer the question how representative 
our purposeful chosen sample is. For this reason, we did not present data from the standardized measures we used, for example, regarding the perceived need, mental health diagnosis, or the severity of psychosocial problems. These results would not have been generalizable and therefore misleading. Further work should integrate quantitative measures of actual illness, illness severity, and actual health behavior as in other populations, it seems to play an important role in help-seeking behavior. ${ }^{25,26}$

Another limitation is, that we did not want to achieve an in-depth understanding of the whole veterans' life, their goals, their motivations, etc. and the social implications of the process of help-seeking. We focused solely on beliefs or attitudes regarding mental health service use and therefore might have neglected relevant contextual factors. There is other qualitative work that has a focus on understanding these contextual factors. ${ }^{27}$ However, these studies, on the other hand, lack an integration within a well-established theoretical framework.

There is a growing scientific literature on the influence of individual factors, for example, masculinity on help-seeking behavior in general ${ }^{10-13}$ and especially among veterans. ${ }^{14,15}$ Our results are in line with other actual research ${ }^{16}$ and suggest that further attention should be paid to the role of masculinity and/or military culture as a factor influencing the beliefs of former soldiers on help-seeking. Both concepts might be linked by Connell's concept of hegemonic masculinity. ${ }^{17}$ Future studies should consider these gender differences. ${ }^{18}$

As far as we know, the only comparable work conducted so far among soldiers was an assessment of beliefs about mental health care in Iraq veterans. ${ }^{19}$ In line with this investigation, we found that evaluation by others, especially fear of stigmatization, was one of the important concerns veterans expressed. Organizational difficulties were also mentioned. Stecker et al described them as "interference of immediate help" or "getting time off from work", we subsumed them under the term "incapability." Most importantly, coping styles that do not include seeking help but deal with problems on their own were found in the salient beliefs of both samples ("autarky"). A difference seems to be the fear of discrimination within the military itself. Stecker et al reported that most respondents thought that their decision to seek help would be supported. In another study by Stecker using telephone interviews and a brief introduction to cognitive behavioral therapy, four categories of beliefs were associated with the decision about seeking treatment: concerns about treatment, which we would subsume under "ineffectiveness", emotional readiness for treatment ("autarky"), stigma (16\%), and logistical issues ( $8 \%$ ) ("incapability"). ${ }^{20}$ In contrast to their results, our sample was fearful about disclosing their mental health problems to others. Other investigations of health beliefs among veterans ${ }^{21-24}$ also highlight the problem of beliefs concerning "ineffectiveness" of psychotherapy. These studies conclude that beliefs on the effectiveness of psychotherapy is directly correlated to their use.

\section{Conclusion}

Our results may have a certain impact on how to address mental health issues among veterans. In particular, care providers and policy makers should take into account the autarky beliefs of the targeted population when designing campaigns and descriptions of mental health programs. Advertisements for the effectiveness of psychotherapy should be designed. Consideration of the normative beliefs of German veterans ("Heteronomy"), addressing not only the soldier himself but also informing relatives and superiors might also be helpful.

\section{Disclosure}

The authors report no conflicts of interest in this work.

\section{References}

1. Wittchen H, Schönfeld S, Kirschbaum C, et al. Traumatic experiences and posttraumatic stress disorder in soldiers following deployment abroad: how big is the hidden problem? Dtsch Arztebl Int. 2012;109(35-36):559-569.

2. Brewin CR, Andrews B, Hejdenberg J, Stewart L. Objective predictors of delayed-onset post-traumatic stress disorder occurring after military discharge. Psychol Med. 2012;42(10):2119-2126.

3. Andersen RM. National health surveys and the behavioral model of health services use. Med Care. 2008;46(7):647-653.

4. Bradley EH, McGraw SA, Curry L, et al. Expanding the Andersen model: the role of psychosocial factors in long-term care use. Health Serv Res. 2002;37(5):1221-1242.

5. Ajzen I. The theory of planned behavior. Organ Behav Hum Decis Process. 1991;50(2):179-211.

6. Stamer M, Güthlin C, Holmberg C, Karbach U, Patzelt C, Meyer T. [Qualitative Studien in der Versorgungsforschung - Diskussionspapier, Teil 3: Qualität qualitativer Studien]. Gesundheitswesen. 2015;77(12):966-975. German.

7. Dresing T, Pehl T. Manual (on) Transcription. Transcription Conventions, Software Guides and Practical Hints for Qualitative Researchers. 3rd ed. Marburg, Germany: self published. Available from: http:// www.audiotranskription.de/english/transcription-practicalguide.htm. Accessed May 14, 2018.

8. Corbin JM, Strauss AL. Basics of Qualitative Research: Techniques and Procedures for Developing Grounded Theory. 3rd ed. Los Angeles, CA, USA: SAGE Publications; 2008.

9. Teddlie C, Yu F. Mixed methods sampling: a typology with examples. J Mix Methods Res. 2007;1(1):77-100.

10. Wong YJ, Ho MR, Wang S, Miller IS. Meta-analyses of the relationship between conformity to masculine norms and mental health-related outcomes. J Couns Psychol. 2017;64(1):80-93.

11. Krumm S, Checchia C, Koesters M, Kilian R, Becker T. Men's views on depression: a systematic review and metasynthesis of qualitative research. Psychopathology. 2017;50(2):107-124. 
12. Heath PJ, Brenner RE, Vogel DL, Lannin DG, Strass HA. Masculinity and barriers to seeking counseling: the buffering role of self-compassion. J Couns Psychol. 2017;64(1):94-103.

13. Sullivan L, Camic PM, Brown JS. Masculinity, alexithymia, and fear of intimacy as predictors of UK men's attitudes towards seeking professional psychological help. Br J Health Psychol. 2015;20(1): 194-211.

14. Lorber W, Garcia HA. Not supposed to feel this: traditional masculinity in psychotherapy with male veterans returning from Afghanistan and Iraq. Psychotherapy (Chic). 2010;47(3):296-305.

15. Caddick N, Smith B, Phoenix C. Male combat veterans' narratives of PTSD, masculinity, and health. Sociol Health Illn. 2015;37(1): 97-111.

16. Keohane A, Richardson N. Negotiating gender norms to support men in psychological distress. Am J Mens Health. 2018;12(1): $160-171$.

17. Connell RW. Masculinities. 2nd ed. Berkeley, CA, USA: University of California Press; 2005.

18. Dobie DJ, Kivlahan DR, Maynard C, Bush KR, Davis TM, Bradley KA. Posttraumatic stress disorder in female veterans: association with self-reported health problems and functional impairment. Arch Intern Med. 2004;164(4):394-400.

19. Stecker T, Fortney JC, Hamilton F, Ajzen I. An assessment of beliefs about mental health care among veterans who served in Iraq. Psychiatr Serv. 2007;58(10):1358-1361.
20. Stecker T, Shiner B, Watts BV, Jones M, Conner KR. Treatment-seeking barriers for veterans of the Iraq and Afghanistan conflicts who screen positive for PTSD. Psychiatr Serv. 2013;64(3):280-283.

21. DeViva JC, Sheerin CM, Southwick SM, Roy AM, Pietrzak RH, HarpazRotem I. Correlates of VA mental health treatment utilization among $\mathrm{OEF} / \mathrm{OIF} / \mathrm{OND}$ veterans: resilience, stigma, social support, personality, and beliefs about treatment. Psychol Trauma. 2016;8(3):310-318.

22. Rüsch N, Rose $\mathrm{C}$, Holzhausen $\mathrm{F}$, et al. Attitudes towards disclosing a mental illness among German soldiers and their comrades. Psychiatry Res. Epub 2017 Aug 16.

23. Vogt D, Fox AB, Di Leone BA. Mental health beliefs and their relationship with treatment seeking among U.S. OEF/OIF veterans. J Trauma Stress. 2014;27(3):307-313.

24. Vogt D. Mental health-related beliefs as a barrier to service use for military personnel and veterans: a review. Psychiatr Serv. 2011;62(2):135-142.

25. Watson-Singelton NN, Okunoren O, LoParo D, Hunter CD. Emotional benefits and barriers of Psychological Service Scale: initial construction and validation among African American women. J Couns Psychol. 2017;64(6):684-695.

26. Lowinger R. College students' perceptions of severity and willingness to seek psychological help for drug and alcohol problems. Coll Stud J. 2012;46(4):829-833.

27. Desai MU, Pavlo AJ, Davidson L, Harpaz-Rotem I, Rosenheck R. "I want to come home": Vietnam-Era Veterans' presenting for mental health care, roughly 40 years after Vietnam. Psychiatr Q. 2016;87(2):229-239.
Psychology Research and Behavior Management

\section{Publish your work in this journal}

Psychology Research and Behavior Management is an international, peerreviewed, open access journal focusing on the science of psychology and its application in behavior management to develop improved outcomes in the clinical, educational, sports and business arenas. Specific topics covered in the journal include: Neuroscience, memory and decision making; Behavior

\section{Dovepress}

modification and management; Clinical applications; Business and sports performance management; Social and developmental studies; Animal studies. The manuscript management system is completely online and includes a very quick and fair peer-review system, which is all easy to use. Visit http://www. dovepress.com/testimonials.php to read real quotes from published authors. 